\title{
Expression of microRNA and their gene targets are dysregulated in preinvasive breast cancer
}

\author{
Bethany N Hannafon ${ }^{1}$, Paola Sebastiani ${ }^{2}$, Antonio de las Morenas ${ }^{3}$, Jining Lu', Carol L Rosenberg ${ }^{1,3^{*}}$
}

\begin{abstract}
Introduction: microRNA (miRNA) are short, noncoding RNA that negatively regulate gene expression and may play a causal role in invasive breast cancer. Since many genetic aberrations of invasive disease are detectable in early stages, we hypothesized that miRNA expression dysregulation and the predicted changes in gene expression might also be found in early breast neoplasias.

Methods: Expression profiling of 365 miRNA by real-time quantitative polymerase chain reaction assay was combined with laser capture microdissection to obtain an epithelium-specific miRNA expression signature of normal breast epithelium from reduction mammoplasty (RM) $(n=9)$ and of paired samples of histologically normal epithelium (HN) and ductal carcinoma in situ (DCIS) $(n=16)$. To determine how miRNA may control the expression of codysregulated mRNA, we also performed gene expression microarray analysis in the same paired HN and DCIS samples and integrated this with miRNA target prediction. We further validated several target pairs by modulating the expression levels of miRNA in MCF7 cells and measured the expression of target mRNA and proteins.

Results: Thirty-five miRNA were aberrantly expressed between RM, HN and DCIS. Twenty-nine miRNA and 420 mRNA were aberrantly expressed between HN and DCIS. Combining these two data sets with miRNA target prediction, we identified two established target pairs (miR-195:CCND1 and miR-21:NFIB) and tested several novel miRNA:mRNA target pairs. Overexpression of the putative tumor suppressor miR-125b, which is underexpressed in DCIS, repressed the expression of MEMO1, which is required for ErbB2-driven cell motility (also a target of miR125b), and NRIP1/RIP140, which modulates the transcriptional activity of the estrogen receptor. Knockdown of the putative oncogenic miRNA miR-182 and miR-183, both highly overexpressed in DCIS, increased the expression of chromobox homolog 7 (CBX7) (which regulates E-cadherin expression), DOK4, NMT2 and EGR1. Augmentation of CBX7 by knockdown of miR-182 expression, in turn, positively regulated the expression of E-cadherin, a key protein involved in maintaining normal epithelial cell morphology, which is commonly lost during neoplastic progression.

Conclusions: These data provide the first miRNA expression profile of normal breast epithelium and of preinvasive breast carcinoma. Further, we demonstrate that altered miRNA expression can modulate gene expression changes that characterize these early cancers. We conclude that miRNA dysregulation likely plays a substantial role in early breast cancer development.
\end{abstract}

\section{Introduction}

Considerable molecular pathology research has focused on invasive breast cancer (IBC); however, less attention has been given to the preinvasive nonobligate precursor, ductal carcinoma in situ (DCIS). DCIS is the fourth most common cancer diagnosis among women and is present in the vast majority of IBC cases [1]. Women

\footnotetext{
* Correspondence: crosenbe@bu.edu

'Department of Medicine, Boston Medical Center and Boston University

School of Medicine, 72 East Concord Street, Boston, MA 02118, USA

Full list of author information is available at the end of the article
}

diagnosed with DCIS are at an increased risk of subsequently developing IBC, and, when examined, DCIS and IBC also share many of the same genetic features. However, there is an increased need to better understand the early genetic events and identify biomarkers that are present prior to IBC. microRNA (miRNA) have emerged as a new class of gene regulators that may serve as both molecular biomarkers and novel therapeutic targets. In this study, we sought to investigate miRNA expression changes and their consequences in preinvasive breast cancer.

\section{C) Biomed Central}


miRNA are short, non-protein-coding RNA that exert posttranscriptional control over their mRNA targets through the mechanism of RNA interference. By complementary binding to the 3' untranslated region of target mRNA, miRNA promote mRNA destabilization, thereby inducing translational repression [2]. It has been demonstrated that miRNA control major cellular processes, including metabolism, developmental timing, stem cell division, cell growth and differentiation and apoptosis [3-5]. Given this expansive role, it is unsurprising that their effect on mRNA expression contributes to the pathogenesis of many diseases, including cancer [6,7]. To date, more than 900 miRNA have been identified in humans, constituting more than $1 \%$ of the total coding genome. It is predicted that more than $60 \%$ of mRNA may be targeted and that a single miRNA may target as many as 200 mRNA, thus making miRNA the largest class of gene regulators [8-10].

Several studies have established the role of miRNA in the pathogenesis of IBC. For example, abnormal miRNA expression has been described in breast cancer cell lines and in bulk primary normal and cancerous breast tissues [11-13]. In this setting, miRNA expression has correlated with specific breast cancer biopathologic features, such as estrogen receptor (ER) and progesterone receptor (PR) expression, tumor stage, vascular invasion or proliferation index. In addition, many miRNA that are consistently downregulated may act as tumor suppressors, for example, miR-206, miR-17-5p, miR-125a, miR-125b and the let-7 family, and many that are consistently upregulated may acts as oncogenes, for example, miR-21, miR-10b and miR-27a. Other studies have shown that miRNA exhibit a specific spatial distribution of expression within breast epithelium [14].

Almost all human breast cancers arise in the epithelial compartment, likely as a result of the transformation of epithelial cells, although the surrounding stroma and microenvironment play a crucial role in tumor progression. Therefore, the present work is focused on the genetic changes that occur within the epithelial cell population.

We hypothesized that miRNA expression might be dysregulated prior to $\mathrm{IBC}$, that these changes might be associated with mRNA expression changes and that together these might help to elucidate important steps in early breast tumorigenesis. Therefore, to first obtain a profile of normal miRNA expression, we profiled miRNA in normal epithelium from healthy controls undergoing reduction mammoplasty (RM). Next, to obtain a profile of miRNA dysregulated prior to invasion, we examined miRNA expression in histologically normal (HN) epithelium and compared this to paired samples of adjacent DCIS. We then integrated the HN:DCIS miRNA expression profile with the gene expression profile from the same samples and used miRNA target prediction programs to identify putative miRNA:mRNA functional interactions. We then selected three candidate miRNA (miR-125b, miR-182 and miR-183) and six of their putative target genes (MEMO1, NRIP1, CBX7, DOK4, NMT2, and $E G R 1$ ) for validation. This study represents the first report of a miRNA expression profile in normal breast epithelium and the first integrated analysis of dysregulated miRNA and mRNA expression in paired $H N$ and DCIS samples. Many of the dysregulated miRNA identified in DCIS have previously been identified in IBC. Our data suggest an important role for miRNA in determining the parallel gene expression changes that characterize the earliest stage of breast disease.

\section{Materials and methods}

\section{Tissue sample acquisition and preparation}

Primary breast tissues not needed for diagnosis were obtained at Boston Medical Center from patients undergoing RM and breast cancer surgery (prior to any chemo- or radiation therapy). All samples were deidentified and assigned a number at the time of collection; therefore, informed consent was not required according to our specimen collection protocol preapproved by the Boston University Medical Center Institutional Review Board. Samples were processed as described previously [15]. Epithelia from three groups were examined: normal breast tissue $(n=9)$ from RM (mean age, 52.2 years; age range, 44 to 75 years) and paired samples of $\mathrm{HN}$ and DCIS $(n=16)$ from eight individuals undergoing cancer surgery. Hematoxylin and eosin-stained sections were reviewed by a pathologist (AdlM) to verify normal epithelia and preinvasive lesions.

\section{Laser capture microdissection and RNA isolation}

Laser capture microdissection (LCM) was performed as described previously [15-17] to collect breast epithelial cells of normal appearing ductal tissue (RM and HN) and epithelial cells of identified regions of DCIS. Total RNA was isolated using the RNAqueous miRNA Isolation Kit (Ambion, Austin, TX, USA) and treated with DNase I according to the manufacturer's instructions. RNA to be utilized for gene expression analysis was processed as described previously $[15,16]$. The pooled RM sample was prepared by combining $400 \mathrm{ng}$ of total RNA from each of the nine RM samples.

\section{miRNA expression profiling and statistical analysis} cDNA was synthesized from $800 \mathrm{ng}$ (100 ng/multiplex pool) with the TaqMan miRNA Reverse Transcription Kit (Applied Biosystems, Foster City, CA, USA), according to manufacturer's instructions. miRNA expression was measured by real-time quantitative polymerase chain reaction ( $\mathrm{RT}-\mathrm{qPCR}$ ) assay utilizing the TaqMan 
Human miRNA Array Panel (version 1.0, based on miRBase version 9.2; Applied Biosystems) and assayed on the 7900 Real-Time PCR System (Applied Biosystems), according to the manufacturer's instructions. miRNA expression data are available from the National Center for Biotechnology Gene Expression Omnibus (GEO) [18] at accession number [GEO:GSE24509].

All probes with threshold cycles $(\mathrm{Ct})=40$ in more than two of three pooled RM (PRM) replicates or more than six of eight HN samples and more than six of eight DCIS samples were considered "nonexpressed" and removed. Remaining $\mathrm{Ct}$ values were global median normalized by transforming all expression values by rescaling to a target value of $12(\Delta \mathrm{Ct})$. Relative changes in miRNA expression among each comparison (HN-PRM, DCIS-PRM and DCIS-HN) were assessed $(\Delta \Delta \mathrm{Ct})$. A variance correction was applied to account for the pooled samples as suggested by Churchill [19], and a $t$-test was performed. $P<$ 0.005 in at least one of the comparisons was considered statistically significant. To address the issue of multiple comparisons, we highlight the results that remain significant using two valid procedures: the more restrictive Bonferroni correction $(P<0.00025)$ and the less restrictive false discovery rate $<0.05(P<0.017)$, which typically results in a greater number of significant results. The relative fold change for each comparison was calculated by $2^{\wedge-\Delta \Delta C t}$. Heatmaps were generated using the Heatplus package in Bioconductor [20].

\section{Gene expression profiling and statistical analysis}

Gene expression analysis was measured on the U133A GeneChip (Affymetrix, Santa Clara, CA, USA). All microarray analyses were performed at the Boston University Microarray Facility as previously described [15]. The paired data were assembled as follows: 12 paired samples (six HN and six DCIS) were pulled from the data published by Emery et al. [15], two HN samples were pulled from the data published by Graham et al. [21], and the two matching pairs of DCIS samples (combined to equal 16 paired samples) were collected and processed from tissue acquired from the same patient. Array data were analyzed as previously described [15]. Microarray output data were filtered by removing all probe sets present in $<15 \%$ of all samples. Next, data were analyzed by performing Bayesian Analysis of Differential Gene Expression (BADGE) as previously described by Emery et al. [15] and found online at the BADGE website [22]. The gene expression data are available from GEO under accession number [GEO: GSE24509].

\section{miRNA target prediction}

SigTerms [23] was utilized to extract predictions from PicTar [24], TargetScan (4.1 and 5.1) [25] and miRanda
(Jan 08 and Sep 08) [26]. miRNA target predictions were extracted two separate times, the first using TargetScan release 4.1 and miRanda release Jan 08 and the second using TargetScan release 5.1 and miRanda release Sep 08. The final prediction results are a combination of the two queries. Pearson correlations and associated $P$ values were calculated across all $16 \mathrm{HN}$ and DCIS samples for each of the target pairs identified from the intersection of the programs.

\section{Gene ontology and pathway analysis}

Gene annotation, ontology and pathway analysis were conducted using the Database for Annotation, Visualization and Integrated Discovery [27]. A modified Fisher's exact test/EASE (Enrichment) Score was utilized to calculate the $P$-values.

\section{miRNA pre-miR and anti-miR transient transfection}

MCF7 cells were kindly provided by G. Sonenshein (Tufts-New England Medical Center, Boston, MA, USA) and were maintained in Dulbecco's modified Eagle's medium (Invitrogen, Carlsbad, CA, USA) with $4.5 \mathrm{~g} / \mathrm{l}$ glucose and sodium pyruvate supplemented with $5.8 \mathrm{~g} / \mathrm{l}$ L-glutamine (Cellgro, Manassas, VA, USA), 10\% fetal bovine serum (Sigma-Aldrich, St. Louis, MO, USA) and $1 \%$ penicillin-streptomycin (Cellgro). For all experiments, $5 \times 10^{4}$ cells/well of a 12 -well plate were seeded for 24 hours and then transfected with (1) $100 \mathrm{nM}$ premiR-125b or scrambled negative control sequence (Scramble) or (2) $50 \mathrm{nM}$ Anti-miR-182, Anti-miR-183 or Scramble using the siPORT NeoFX Transfection Agent (Ambion)

\section{RNA extraction cell culture}

Cells were rinsed with $1 \times$ phosphate-buffered saline (PBS) and lysed with $600 \mu \mathrm{l}$ of lysis buffer, and total RNA was isolated with the mirVana Isolation Kit (Ambion) and treated with DNase I, according to the manufacturer's instructions. RNA quantity was determined using Quant-it RiboGreen RNA Quantitation Reagent (Invitrogen) according to the manufacturer's instructions

\section{qRT-PCR for target gene expression}

cDNA from 500 ng of total RNA was synthesized using TaqMan RT reagents according to the manufacturer's instructions. qRT-PCR was performed by diluting RT product in $2 \times$ Universal PCR MasterMix and 20× TaqMan Gene Expression Assay for each gene to be measured: chromobox homolog 7 (CBX7) (Hs00980916_g1), docking protein 4 (DOK4) (Hs00902919_g1), early growth response 1 (EGR1) (Hs00152928_m1), glyceraldehyde 3-phosphate dehydrogenase (GAPDH) (4333764F), mediator of ErbB2driven cell motility (MEMO1) (Hs00831646_uH), N- 
myristoyltransferase 2 (NMT2) (Hs01013924_g1) and nuclear receptor-interacting protein 1 (NRIP1/RIP140) (Hs00942766_s1). PCR reactions were run on the 7500 real-time PCR instrument under the following conditions: hold at $95^{\circ} \mathrm{C}$ for 10 minutes, then 40 cycles of $95^{\circ} \mathrm{C}$ for 15 seconds and $60^{\circ} \mathrm{C}$ for 1 minute. All reagents were purchased from Applied Biosystems. Relative gene expression was assessed using the differences in normalized $\mathrm{Ct}$ $(\Delta \Delta \mathrm{Ct})$ method after normalization to GAPDH. Fold

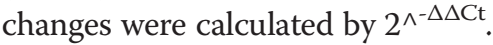

\section{Immunoblot analysis}

Cells were washed with $1 \times$ PBS 48 hours posttransfection and collected in radioimmunoprecipitation assay buffer $(25$ mM Tris- $\mathrm{HCl}$, pH 7.6, $150 \mathrm{mM} \mathrm{NaCl}, 1 \%$ NP-40, 1\% sodium deoxycholate, $0.1 \%$ sodium dodecyl sulfate). Protein $(50 \mu \mathrm{g})$ was electrophoresed through a $4 \%$ to $15 \%$ Tris. $\mathrm{HCl}$ Ready Gel (Bio-Rad, Hercules, CA, USA) under reducing conditions and transferred onto a polyvinylidene fluoride membrane. The membrane was incubated with primary antibodies against $C B X 7$ (ab21873; Abcam, Cambridge, MA, USA), E-cadherin (610181; BD Biosciences, San Jose, CA, USA) and $\beta$ actin (A5441; Sigma-Aldrich). Immune complexes were detected using horseradish peroxidase-conjugated secondary antibodies and the SuperSignal West Pico Chemiluminescent Substrate Kit (Pierce Biotechnology, Rockford, IL, USA).

\section{Results}

miRNA expression profiles of RM, HN and paired DCIS

Our first goal was to generate a set of miRNA expression profiles in primary human healthy and diseased breast epithelia. Therefore, we microdissected 25 samples to enrich for epithelial RNA from 17 patients (see Additional file 1 for representative epithelial lesions) separated into three groups: the control group of normal epithelia from nine patients undergoing RM and the paired diseased groups, which consisted of 16 samples from eight patients (eight samples of $\mathrm{HN}$ and eight samples of adjacent ER- and PR-positive DCIS (Table 1).

Next, to test the reproducibility of the miRNA expression array, we combined equal amounts of RNA from nine RM samples into a pooled RM (PRM). The PRM served both as a heterogeneous biological control and as a technical replicate. The PRM was run in triplicate and showed a high correlation between each replicate with a mean Pearson's correlation of 0.95 (Additional file 2).

\section{miRNA are differentially expressed in normal and preinvasive breast cancer}

By comparing the miRNA expression profiles between PRM, HN and DCIS (see Additional file 3 for a list of miRNA expressed in each group), we found that 35 miRNA were differentially expressed $(P<0.005)$ in at least one comparison (see heatmaps in Figure $1 \mathrm{~A}$ and Additional file 4, as well as data in Table 2). As expected, the fewest differences were found in the HNPRM comparison, where 11 miRNA were different (seven overexpressed and four underexpressed). More than twice that number were different in both the DCIS-PRM and DCIS-HN comparisons, with 29 miRNA being different and 23 of 29 overlapping between these comparisons. In the DCIS-PRM comparison, 17 miRNA were overexpressed and 12 were underexpressed; in the DCIS-HN comparison, 15 miRNA were overexpressed and 14 were underexpressed. It has been noted that miRNA that are present within $50 \mathrm{~kb}$ at the same genetic loci are often coordinately expressed [28]. We examined these 35 miRNA for coordinate expression because of their close genomic proximity. The 35 miRNA were located at 29 different loci, and 16 of 35 miRNA were clustered at seven distinct loci (indicated in Additional file 4). As expected, 14 (88\%) of 16 miRNA $<13 \mathrm{~kb}$ apart were positively correlated, with the exception of miR-17-3p and miR-18a.

Table 1 Paired histologically normal and DCIS sample summary ${ }^{\mathrm{a}}$

\begin{tabular}{|c|c|c|c|c|c|}
\hline Sample & Age, yr & DCIS grade & DCIS histology & ER/PR/HER2 of IDC & IDC grade \\
\hline 379 & 43 & 2 and 3 & Cribiform & $+/+/+$ & 2 \\
\hline 444 & 48 & 2 & Cribiform & $+/+/ \mathrm{NA}$ & Not present \\
\hline 248 & 49 & 1 & Micropapillary & $+/+/ N A$ & 2 \\
\hline 274 & 49 & 2 & Solid & $+/+/-$ & 1 \\
\hline 380 & 53 & 2 and 3 & Solid/cribiform & $+/+/-$ & 2 \\
\hline $446 B$ & 54 & 3 & Comedo/solid & $+/+/-$ & 2 \\
\hline 258 & 65 & 1 and 2 & Cribiform/micropapillary & $+/+/-$ & 2 \\
\hline 405 & 67 & 2 & Micropapillary/cribiform & $+/+/-$ & 2 \\
\hline Mean age & 53.5 & & & & \\
\hline Median age & 51.0 & & & & \\
\hline
\end{tabular}

${ }^{a}$ DCIS, ductal carcinoma in situ; ER, estrogen receptor; PR, progesterone receptor; HER2, human epidermal growth factor receptor 2; IDC, invasive ductal carcinoma in situ; NA, not applicable. 


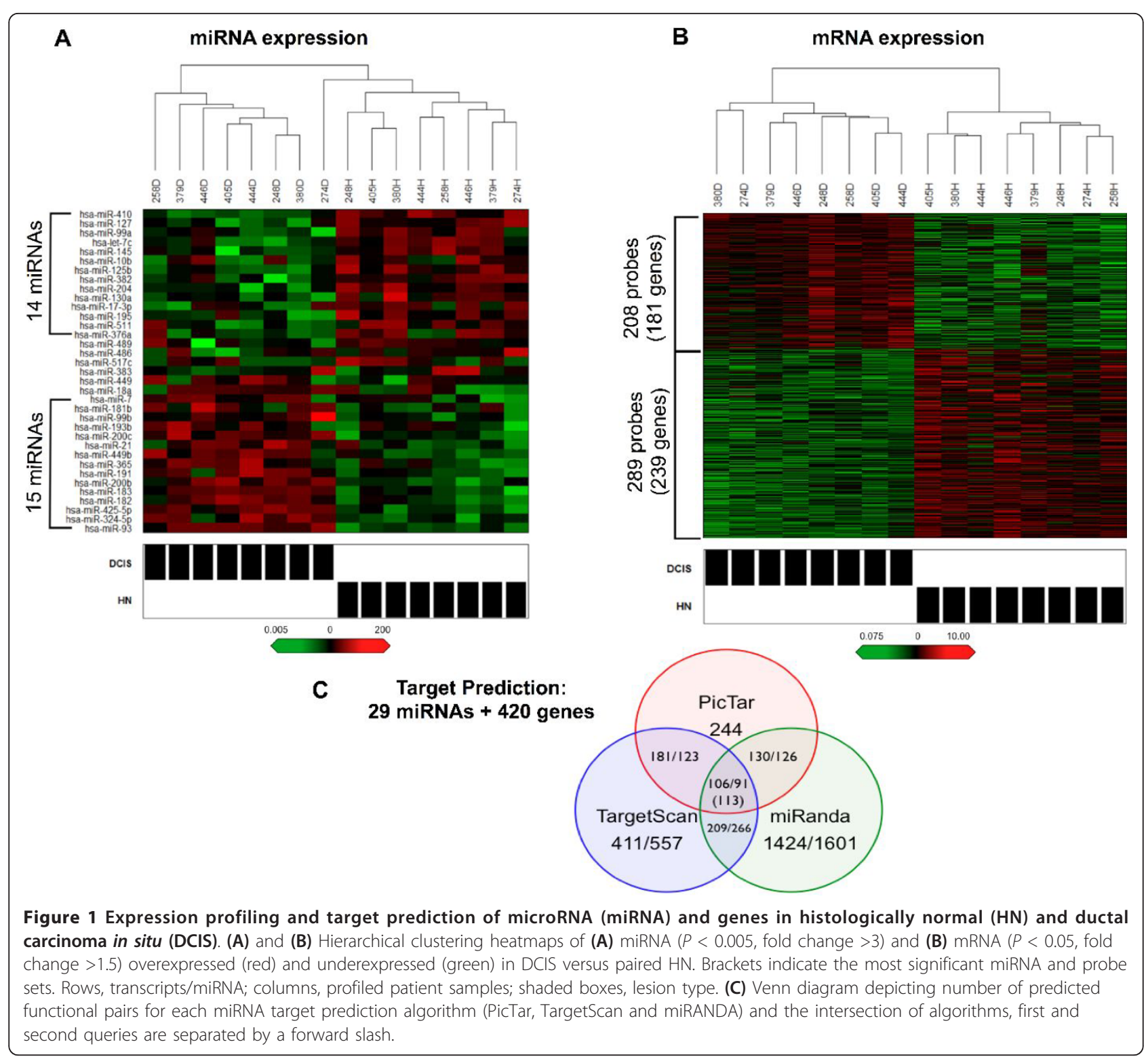

To validate our miRNA data set, we searched the literature to determine whether any of these miRNA are implicated in IBC. Twenty (57\%) of the 35 miRNA have previously been implicated (noted in Table 2) $[13,14,18,29-41]$. Eleven of these 20 miRNA were overexpressed in DCIS compared to HN and PRM (miR181b, miR-200b, miR-200c, miR-18a, miR-21, miR-365, miR-7, miR-182, miR-191, miR-193b and miR-93). The directional change in expression in DCIS of seven (64\%) of these 11 miRNA is consistent with their reported expression in IBC; the exceptions are miR-18a, miR193b, miR-200b and miR-200c. Nine of these 20 miRNA were underexpressed in DCIS compared to HN and PRM (let-7c, miR-10b [14], miR-125b, miR-127, miR145, miR-17-3p, miR-195, miR-204 and miR-383), and the directional change in expression in DCIS of eight (89\%) of these nine miRNA is consistent with their expression in IBC (except miR-195). Overall, 15 (75\%) of 20 miRNA that are dysregulated are concordantly dysregulated in IBC. Of the 29 miRNA dysregulated in DCIS compared to HN, 18 (62\%) of 29 are implicated in IBC and concordant with the reported changes in expression.

\section{Differentially expressed miRNA are predicted to target} differentially expressed genes in HN-DCIS comparison The identification of miRNA targets is crucial to understanding the biological role of miRNA. We have recently shown that gene expression is altered in paired $\mathrm{HN}$ and DCIS epithelial cells [15]. Because mRNA destabilization 
Table 2 Differentially expressed microRNA among pooled reduction mammoplasty, histologically normal and ductal carcinoma in situ ${ }^{\mathrm{a}}$

\begin{tabular}{|c|c|c|c|c|c|c|}
\hline \multirow[b]{2}{*}{ microRNA } & \multicolumn{2}{|c|}{ HN versus PRM } & \multicolumn{2}{|c|}{ DCIS versus PRM } & \multicolumn{2}{|c|}{ DCIS versus $\mathrm{HN}$} \\
\hline & Fold change & $P$ value ${ }^{\mathrm{b}}$ & Fold change & $P$ value ${ }^{b}$ & Fold change & $P$ value $^{\mathrm{b}}$ \\
\hline let-7c [62] & 15.23 & $3.46 \mathrm{E}-03^{\mathrm{C}}$ & 0.31 & $1.25 \mathrm{E}-01$ & 0.03 & $1.19 \mathrm{E}-03^{\mathrm{C}}$ \\
\hline miR-7 [38] & 3.12 & $1.35 \mathrm{E}-01$ & 22.35 & $1.53 \mathrm{E}-03^{\mathrm{C}}$ & 5.19 & 4.92E-02 \\
\hline miR-10b [13,39] & 2.90 & $1.59 \mathrm{E}-01$ & 0.82 & $7.82 \mathrm{E}-01$ & 0.04 & $2.58 \mathrm{E}-03^{\mathrm{c}}$ \\
\hline miR-17-3p [32,40] & 19.04 & $2.14 \mathrm{E}-03^{\mathrm{C}}$ & 2.20 & $2.85 \mathrm{E}-01$ & 0.12 & 1.73E-02 \\
\hline miR-18a [34] & 1.91 & $3.76 \mathrm{E}-01$ & 20.88 & $1.76 \mathrm{E}-03^{\mathrm{C}}$ & 3.53 & 1.12E-01 \\
\hline $\operatorname{miR}-21[13,31,36,40,41]$ & 6.74 & $2.23 \mathrm{E}-02$ & 55.20 & $2.64 \mathrm{E}-04^{c}$ & 20.92 & $3.21 \mathrm{E}-03^{\mathrm{c}}$ \\
\hline miR-93[34] & 7.53 & $1.72 \mathrm{E}-02$ & 193.86 & 3.33E-05d & 160.47 & $1.59 \mathrm{E}-04 \mathrm{~d}$ \\
\hline miR-99a & 1.90 & $3.79 \mathrm{E}-01$ & 0.53 & 3.79E-01 & 0.02 & $9.19 \mathrm{E}-04^{\mathrm{C}}$ \\
\hline miR-99b & 3.08 & $1.39 \mathrm{E}-01$ & 14.84 & $3.66 \mathrm{E}-03^{c}$ & 6.24 & 3.33E-02 \\
\hline miR-125b [13,29] & 0.93 & $9.24 \mathrm{E}-01$ & 0.08 & $5.39 \mathrm{E}-03^{c}$ & 0.05 & $4.03 \mathrm{E}-03^{\mathrm{C}}$ \\
\hline miR-127 [30,31] & 1.77 & 4.30E-01 & 0.25 & 7.81E-02 & 0.02 & $5.30 \mathrm{E}-04^{\mathrm{c}}$ \\
\hline miR-130a & 0.29 & $1.06 \mathrm{E}-01$ & 0.01 & $1.38 \mathrm{E}-04^{d}$ & 0.09 & 1.01E-02 \\
\hline miR-145 [13,14] & 3.00 & $1.47 \mathrm{E}-01$ & 0.80 & $7.52 \mathrm{E}-01$ & 0.03 & $1.20 \mathrm{E}-03^{\mathrm{C}}$ \\
\hline miR-181b $[31,40]$ & 3.40 & $1.11 \mathrm{E}-01$ & 14.90 & $3.64 \mathrm{E}-03^{\mathrm{C}}$ & 5.46 & 4.42E-02 \\
\hline miR-182 [33] & 2.00 & $3.45 \mathrm{E}-01$ & 106.24 & $8.54 \mathrm{E}-05^{\mathrm{d}}$ & 72.35 & 4.55E-04 \\
\hline miR-183 & 2.52 & $2.15 \mathrm{E}-01$ & 19.06 & $2.14 \mathrm{E}-03^{\mathrm{C}}$ & 51.88 & $7.38 \mathrm{E}-04^{\mathrm{c}}$ \\
\hline miR-191 [13] & 6.75 & $2.23 \mathrm{E}-02$ & 78.21 & $1.43 \mathrm{E}-04^{\mathrm{d}}$ & 31.59 & 1.60E-03c \\
\hline miR-193b [18] & 2.20 & $2.84 \mathrm{E}-01$ & 15.67 & $3.25 \mathrm{E}-03^{c}$ & 6.87 & 2.73E-02 \\
\hline miR-195 [35] & 1.37 & $6.57 \mathrm{E}-01$ & 0.06 & $2.78 \mathrm{E}-03^{\mathrm{c}}$ & 0.13 & 2.15E-02 \\
\hline miR-200b [37] & 1.70 & 4.63E-01 & 6.07 & $2.86 \mathrm{E}-02$ & 51.31 & $7.50 \mathrm{E}-04^{\mathrm{c}}$ \\
\hline miR-200c [37] & 1.90 & $3.80 \mathrm{E}-01$ & 26.41 & $1.08 \mathrm{E}-03^{c}$ & 19.98 & $3.48 \mathrm{E}-03^{\mathrm{C}}$ \\
\hline miR-204 [13] & 0.77 & 7.12E-01 & 0.04 & $1.32 \mathrm{E}-03^{\mathrm{C}}$ & 0.08 & $8.12 \mathrm{E}-03^{\mathrm{C}}$ \\
\hline miR-324-5p & 2.86 & $1.64 \mathrm{E}-01$ & 24.38 & $1.28 \mathrm{E}-03^{\mathrm{C}}$ & 92.53 & $3.24 \mathrm{E}-04^{\mathrm{c}}$ \\
\hline miR-365 [31] & 4.05 & 7.45E-02 & 17.65 & $2.51 \mathrm{E}-03^{\mathrm{C}}$ & 25.05 & $2.35 \mathrm{E}-03^{\mathrm{C}}$ \\
\hline miR-376a & 0.45 & $2.73 \mathrm{E}-01$ & 0.06 & $3.14 \mathrm{E}-03^{\mathrm{C}}$ & 0.24 & $7.91 \mathrm{E}-02^{\mathrm{C}}$ \\
\hline miR-382 & 2.03 & $3.32 \mathrm{E}-01$ & 0.11 & $1.20 \mathrm{E}-02^{c}$ & 0.06 & $4.71 \mathrm{E}-03^{\mathrm{C}}$ \\
\hline miR-383 [34] & 0.05 & $2.15 \mathrm{E}-03^{c}$ & 0.01 & $1.58 \mathrm{E}-04^{\mathrm{d}}$ & 0.62 & $5.18 \mathrm{E}-01$ \\
\hline miR-410 & 0.96 & $9.56 \mathrm{E}-01$ & 0.15 & $2.33 \mathrm{E}-02^{c}$ & 0.00 & $1.11 \mathrm{E}-04^{\mathrm{d}}$ \\
\hline miR-425-5p & 1.38 & $6.57 \mathrm{E}-01$ & 9.47 & $1.01 \mathrm{E}-02^{c}$ & 74.46 & 4.37E-04 \\
\hline miR-449a & 10.65 & $7.71 \mathrm{E}-03^{\mathrm{C}}$ & 15.12 & $3.52 \mathrm{E}-03^{\mathrm{C}}$ & 2.53 & 2.23E-01 \\
\hline miR-449b & 0.79 & 7.37E-01 & 11.57 & $6.39 \mathrm{E}-03^{c}$ & 21.20 & $3.13 \mathrm{E}-03^{\mathrm{C}}$ \\
\hline miR-486 & 0.02 & $2.06 \mathrm{E}-04^{d}$ & 0.01 & $9.73 E-05^{d}$ & 0.34 & 1.65E-01 \\
\hline miR-489 & 0.06 & $2.73 \mathrm{E}-03^{c}$ & 0.10 & $8.61 \mathrm{E}-03^{\mathrm{C}}$ & 0.25 & 8.62E-02 \\
\hline miR-511 & 0.40 & 2.20E-01 & 0.07 & $3.72 \mathrm{E}-03^{\mathrm{C}}$ & 0.18 & 4.11E-02 \\
\hline $\operatorname{miR}-517^{c}$ & 0.07 & $3.48 \mathrm{E}-03^{\mathrm{C}}$ & 0.01 & $1.29 E-04^{d}$ & 0.36 & $1.82 \mathrm{E}-01$ \\
\hline
\end{tabular}

${ }^{a}$ RM, reduction mammoplasty; PRM, pooled reduction mammoplasty; HN, histologically normal; DCIS, ductal carcinoma in situ; microRNA in boldface type have previously been implicated in invasive breast cancer; ${ }^{\mathrm{b}} P$ value determined by Student's $t$-test; ${ }^{\mathrm{C}} P<1.7 \mathrm{E}-02$ implies significance with a false-discovery rate of 0.05 ; ${ }^{\mathrm{d}} P<2.5 \mathrm{E}-04$ implies significance after the Bonferroni correction; fold change in expression between comparisons was considered significant if $P<5 \mathrm{E}-02$.

is a mechanism of miRNA-mediated gene repression [39], we sought to determine whether any of the 29 miRNA altered in the HN-DCIS comparison may participate in the regulation of these differentially expressed genes through this mechanism. First, we examined the gene expression profile from the same 16 paired $H N$ and DCIS samples. Data were analyzed by BADGE. BADGE uses a model-averaging approach to calculate the posterior probability of a fold change $>1$ for each probe set and ranks the genes, so that probe sets with a very small probability $(<0.025)$ or a very large one $(>0.975)$ are considered differentially expressed. On the basis of the BADGE analysis, we selected the probe sets in which the probability of a fold change $>1.5$ was either $>0.975$ or $<$ 0.025 . These probe sets were further analyzed using a linear mixed model with lognormal errors and random effects to account for patient matching across probe sets. On the basis of this analysis, we obtained a set of 497 probe sets (420 genes) that were differentially expressed $(P$ $<0.05$, fold change $>1.5$ ) between HN and DCIS, 208 probe sets (181 genes) that were overexpressed and 289 probe sets (239 genes) that were underexpressed (Figure 
Table 3 Expression correlation of microRNA and inversely expressed predicted targets ${ }^{a}$

\begin{tabular}{|c|c|c|c|c|c|c|}
\hline \multicolumn{2}{|c|}{$\begin{array}{l}\text { microRNA } \\
\text { expression }\end{array}$} & \multicolumn{3}{|c|}{ Gene expression } & \multicolumn{2}{|c|}{ miRNA:mRNA } \\
\hline miRNA & $\begin{array}{l}\text { Fold } \\
\text { change }\end{array}$ & Probe ID & Gene symbols, gene names & $\begin{array}{l}\text { Fold } \\
\text { change }\end{array}$ & $\begin{array}{l}\text { Expression } \\
\text { correlation }\end{array}$ & $P$ value $^{\mathrm{b}}$ \\
\hline \multirow[t]{5}{*}{ let- $7^{c}$} & 0.03 & 203481_at & C10ORF6, chromosome 10 open reading frame 6 & 1.58 & -0.58 & $1.88 \mathrm{E}-02$ \\
\hline & & 218567_x_at & DPP3, dipeptidylpeptidase 3 & 2.31 & -0.49 & $5.4 \mathrm{E}-02$ \\
\hline & & 203358_s_at & EZH2, enhancer of zeste homolog 2 (Drosophila) & 2.36 & -0.64 & 7.69E-03 \\
\hline & & 209283_at & $\begin{array}{l}\text { SLC2OA1, solute carrier family } 20 \text { (phosphate transporter), } \\
\text { member } 1\end{array}$ & 2.06 & -0.30 & 2.53E-01 \\
\hline & & 203358_s_at & TRIB1, tribbles homolog 1 (Drosophila) & 1.77 & -0.48 & $5.84 \mathrm{E}-02$ \\
\hline miR-10b & 0.04 & 202357_s_at & SDC1, syndecan 1 & 2.06 & -0.28 & 2.96E-01 \\
\hline \multirow[t]{3}{*}{ miR-125b } & 0.05 & 203744_at & HMGB3, high-mobility group box 3 & 2.13 & -0.61 & 1.27E-02 \\
\hline & & 209613_s_at & NRIP1, nuclear receptor interacting protein 1 & 2.25 & -0.39 & $1.36 \mathrm{E}-01$ \\
\hline & & 213004_at & MEMO1, mediator of cell motility 1 & 1.73 & -0.59 & $1.54 \mathrm{E}-02$ \\
\hline \multirow[t]{6}{*}{ miR-17-3p } & 0.12 & 203744_at & HMGB3, high-mobility group box 3 & 2.13 & -0.49 & 5.66E-02 \\
\hline & & 212446_s_at & LASS6, LAG1 longevity assurance homolog 6 & 1.78 & -0.31 & 2.38E-01 \\
\hline & & 211653_x_at & MAP7, microtubule-associated protein 7 & 1.73 & -0.49 & 5.19E-02 \\
\hline & & 213492_at & SERP1, stress-associated endoplasmic reticulum protein 1 & 1.80 & -0.23 & $3.84 \mathrm{E}-01$ \\
\hline & & 203213_at & SAR1B, SAR1 gene homolog B (Saccharomyces cerevisiae) & 1.95 & -0.07 & 8.03E-01 \\
\hline & & 202381_at & ADAM9, ADAM metallopeptidase domain 9 & 2.04 & -0.45 & 7.89E-02 \\
\hline \multirow[t]{5}{*}{ miR-181b } & 5.46 & 221234_s_at & $\begin{array}{c}\text { BACH2, BTB and CNC homology } 1 \text { basic leucine zipper } \\
\text { transcription factor } 2\end{array}$ & 0.47 & -0.30 & $2.62 \mathrm{E}-01$ \\
\hline & & 212914_at & CBX7, chromobox homolog 7 & 0.44 & -0.30 & 2.67E-01 \\
\hline & & $\begin{array}{c}\text { 204753_s_at } \\
\text { 204755_x_at } \\
\text { 204754_at }\end{array}$ & HLF, hepatic leukemia factor & $\begin{array}{l}0.24 \\
0.28 \\
0.31\end{array}$ & $\begin{array}{l}-0.19 \\
-0.52 \\
-0.45\end{array}$ & $\begin{array}{l}4.84 \mathrm{E}-01 \\
3.82 \mathrm{E}-02 \\
7.70 \mathrm{E}-02\end{array}$ \\
\hline & & 204567_s_at & NMT2, N-myristoyltransferase 2 & 0.58 & -0.35 & 1.81E-01 \\
\hline & & $\begin{array}{l}\text { 202274_at } \\
\text { 200974_at }\end{array}$ & $\begin{array}{r}\text { NR3C1, nuclear receptor subfamily } 3 \text {, group C, member } 1 \\
\text { (glucocorticoid receptor) }\end{array}$ & $\begin{array}{l}0.46 \\
0.57\end{array}$ & $\begin{array}{l}-0.44 \\
-0.57\end{array}$ & $\begin{array}{l}8.86 \mathrm{E}-02 \\
2.21 \mathrm{E}-02\end{array}$ \\
\hline \multirow[t]{13}{*}{ miR-182 } & 72.35 & 221234_s_at & $\begin{array}{c}\text { BACH2, BTB and CNC homology } 1 \text { basic leucine zipper } \\
\text { transcription factor } 2\end{array}$ & 0.47 & -0.73 & $1.41 \mathrm{E}-03$ \\
\hline & & $\begin{array}{l}\text { 210347_s_at } \\
\text { 219497_s_at } \\
\text { 219498_s_at }\end{array}$ & BCL11A, B-cell CLL/lymphoma 11A & $\begin{array}{l}0.27 \\
0.42 \\
0.43\end{array}$ & $\begin{array}{l}-0.65 \\
-0.69 \\
-0.80\end{array}$ & $\begin{array}{l}6.31 \mathrm{E}-03 \\
2.86 \mathrm{E}-03 \\
2.19 \mathrm{E}-04\end{array}$ \\
\hline & & 221530_s_at & BHLHB3, basic helix-loop-helix domain containing, class B, 3 & 0.47 & -0.55 & 2.71E-02 \\
\hline & & $\begin{array}{l}\text { 204851_s_at } \\
\text { 204850_s_at }\end{array}$ & DCX, doublecortex; lissencephaly, X-linked (doublecortin) & $\begin{array}{l}0.13 \\
0.30\end{array}$ & $\begin{array}{l}-0.83 \\
-0.67\end{array}$ & $\begin{array}{l}\text { 7.48E-05 } \\
\text { 4.63E-03 }\end{array}$ \\
\hline & & 209691_s_at & DOK4, docking protein 4 & 0.56 & -0.53 & $3.65 \mathrm{E}-02$ \\
\hline & & $\begin{array}{l}\text { 209905_at } \\
\text { 214651_s_at }\end{array}$ & HOXA9, homeobox A9 & $\begin{array}{l}0.10 \\
0.31\end{array}$ & $\begin{array}{l}-0.64 \\
-0.55\end{array}$ & $\begin{array}{l}8.18 \mathrm{E}-03 \\
2.63 \mathrm{E}-02\end{array}$ \\
\hline & & 64900_at & LPHN2, latrophilin 2 & 0.37 & -0.62 & 9.87E-03 \\
\hline & & 219497_s_at & PRKD1, protein kinase D1 & 0.54 & -0.59 & $1.61 \mathrm{E}-02$ \\
\hline & & 210735_s_at & RIMS3, regulating synaptic membrane exocytosis 3 & 0.52 & -0.73 & $1.25 \mathrm{E}-03$ \\
\hline & & 205022_s_at & FOXN3, checkpoint repressor 1 & 0.50 & -0.67 & 4.40E-03 \\
\hline & & 221935_s_at & NCAM1, neural cell adhesion molecule 1 & 0.43 & -0.41 & 1.19E-01 \\
\hline & & 212914_at & CBX7, chromobox homolog 7 & 0.44 & -0.57 & $2.22 \mathrm{E}-02$ \\
\hline & & 204567_s_at & NMT2, N-myristoyltransferase 2 & 0.58 & -0.26 & $3.26 \mathrm{E}-01$ \\
\hline \multirow[t]{4}{*}{ miR-183 } & 51.88 & 221234_s_at & $\begin{array}{c}\text { BACH2, BTB and CNC homology } 1 \text { basic leucine zipper } \\
\text { transcription factor } 2\end{array}$ & 0.47 & -0.75 & 7.83E-04 \\
\hline & & $\begin{array}{l}\text { 204851_s_at } \\
\text { 204850_s_at } \\
\end{array}$ & DCX, doublecortex; lissencephaly, X-linked (doublecortin) & $\begin{array}{l}0.13 \\
0.30\end{array}$ & $\begin{array}{l}-0.82 \\
-0.80\end{array}$ & $\begin{array}{l}1.06 \mathrm{E}-04 \\
2.16 \mathrm{E}-04\end{array}$ \\
\hline & & 201693_s_at & EGR1, early growth response 1 & 0.45 & -0.61 & $1.12 \mathrm{E}-02$ \\
\hline & & $\begin{array}{l}\text { 202274_at } \\
\text { 200974_at }\end{array}$ & $\begin{array}{c}N R 3 C 1 \text {, nuclear receptor subfamily } 3 \text {, group C, member } 1 \\
\text { (glucocorticoid receptor) }\end{array}$ & $\begin{array}{l}0.46 \\
0.57\end{array}$ & $\begin{array}{l}-0.70 \\
-0.45\end{array}$ & $\begin{array}{l}2.77 \mathrm{E}-03 \\
8.08 \mathrm{E}-02\end{array}$ \\
\hline miR-195 & 0.13 & 217852_s_at & ARL8B, ADP ribosylation factor-like $8 \mathrm{~B}$ & 1.64 & -0.31 & 2.49E-01 \\
\hline
\end{tabular}


Table 3 Expression correlation of microRNA and inversely expressed predicted targets ${ }^{\mathbf{a}}$ (Continued)

\begin{tabular}{|c|c|c|c|c|c|c|}
\hline & & 208712_at & CCND1, cyclin D1 [43] & 2.30 & -0.33 & $2.19 \mathrm{E}-01$ \\
\hline & & 208653_s_at & CD164, CD164 molecule, sialomucin & 2.40 & -0.54 & $3.16 \mathrm{E}-02$ \\
\hline & & 202596_at & ENSA, endosulfine $\alpha$ & 2.03 & -0.37 & $1.54 \mathrm{E}-01$ \\
\hline & & 211653_x_at & MAP7, microtubule-associated protein 7 & 1.73 & -0.52 & 4.00E-02 \\
\hline & & 221935_s_at & RAD23B, RAD23 homolog B & 1.79 & -0.08 & 7.61E-01 \\
\hline & & 201341_at & TMEM33, transmembrane protein 33 & 1.62 & -0.30 & 2.64E-01 \\
\hline & & $\begin{array}{l}\text { 212464_s_at } \\
\text { 216442_x_at }\end{array}$ & WWP1, WW domain containing E3 ubiquitin protein ligase 1 & $\begin{array}{l}2.79 \\
2.83\end{array}$ & $\begin{array}{l}-0.49 \\
-0.25\end{array}$ & $\begin{array}{l}5.57 \mathrm{E}-02 \\
5.57 \mathrm{E}-02\end{array}$ \\
\hline miR-204 & 0.08 & 217852_s_at & $A R L 8 B, A D P$-ribosylation factor-like $8 B$ & 1.64 & -0.27 & $3.06 \mathrm{E}-01$ \\
\hline & & 213492_at & SERP1, stress-associated endoplasmic reticulum protein 1 & 1.80 & -0.57 & 2.22E-02 \\
\hline miR-21 & 20.92 & $\begin{array}{l}\text { 218992_at } \\
\text { 219060_at }\end{array}$ & NFIB, nuclear factor I/B [42] & $\begin{array}{l}0.43 \\
0.52\end{array}$ & $\begin{array}{l}-0.75 \\
-0.69\end{array}$ & $\begin{array}{l}9.15 \mathrm{E}-04 \\
3.28 \mathrm{E}-03\end{array}$ \\
\hline miR-7 & 5.19 & 213492_at & COL2A1, collagen type $\|, \alpha 1$ & 0.51 & -0.12 & $6.61 \mathrm{E}-01$ \\
\hline & & 204359_at & FLRT2, fibronectin leucine-rich transmembrane protein 2 & 0.35 & -0.49 & $5.36 \mathrm{E}-02$ \\
\hline & & 206765_at & $\begin{array}{l}\text { KCNJ2, potassium inwardly rectifying channel, subfamily } \mathrm{J} \text {, } \\
\text { member } 2\end{array}$ & 0.33 & -0.73 & $1.35 \mathrm{E}-03$ \\
\hline & & 214112_s_at & SNCA, synuclein $\alpha$ & 0.48 & -0.54 & $3.00 \mathrm{E}-02$ \\
\hline & & 205022_s_at & FOXN3, checkpoint repressor 1 & 0.50 & -0.61 & $1.22 \mathrm{E}-02$ \\
\hline miR-93 & 160.47 & $\begin{array}{l}\text { 210347_s_at } \\
\text { 219497_s_at } \\
\text { 219498_s_at }\end{array}$ & BCL11A, B-cell CLL/lymphoma 11A & $\begin{array}{l}0.27 \\
0.42 \\
0.43\end{array}$ & $\begin{array}{l}-0.75 \\
-0.72 \\
-0.71 \\
\end{array}$ & $\begin{array}{l}7.40 \mathrm{E}-04 \\
1.51 \mathrm{E}-03 \\
2.11 \mathrm{E}-03 \\
\end{array}$ \\
\hline & & $\begin{array}{c}\text { 204753_s_at } \\
\text { 204755_x_at } \\
\text { 204754_at }\end{array}$ & HLF, hepatic leukemia factor & $\begin{array}{l}0.24 \\
0.28 \\
0.31\end{array}$ & $\begin{array}{l}-0.68 \\
-0.81 \\
-0.81\end{array}$ & $\begin{array}{l}3.60 \mathrm{E}-03 \\
1.44 \mathrm{E}-04 \\
1.49 \mathrm{E}-04\end{array}$ \\
\hline & & $\begin{array}{l}\text { 218992_at } \\
\text { 219060_at }\end{array}$ & $N F I B$, nuclear factor $I / B$ & $\begin{array}{l}0.43 \\
0.52\end{array}$ & $\begin{array}{l}-0.74 \\
-0.65\end{array}$ & $\begin{array}{l}1.14 \mathrm{E}-03 \\
6.30 \mathrm{E}-03\end{array}$ \\
\hline & & 203963_at & $R G L 1$, ral guanine nucleotide dissociation stimulator-like 1 & 0.53 & -0.58 & $1.79 \mathrm{E}-02$ \\
\hline & & $\begin{array}{c}\text { 204422_s_at } \\
\text { 205117_at }\end{array}$ & TXNIP, thioredoxin-interacting protein & $\begin{array}{l}0.36 \\
0.49\end{array}$ & $\begin{array}{l}-0.69 \\
-0.57\end{array}$ & $\begin{array}{l}2.96 \mathrm{E}-03 \\
2.14 \mathrm{E}-02\end{array}$ \\
\hline
\end{tabular}

${ }^{a}$ miRNA, microRNA; miRNA:target mRNA pairs tested in this study are indicated by boldface type, and previously confirmed targets from the literature are indicated by boldface italicized type, ${ }^{\mathrm{b}} P$ value determined by Student's $t$-test.

1B). The list of probe sets and mean expression values is provided in Additional file 5.

We then combined the two expression profiles to identify putative miRNA:mRNA functional pairs linking these $420 \mathrm{mRNA}$ and 29 miRNA. To increase specificity (at the cost of lower sensitivity), we integrated results of three target prediction programs and examined only the intersection. We found that 113 unique miRNA:mRNA target pairs were predicted by all three programs, composed of 74 genes and 13 miRNA (Figure 1C).

Returning to the expression data, we found that 59 of 113 miRNA:mRNA pairs (45 mRNA and 12 miRNA) were inversely expressed and that 54 of 113 miRNA: mRNA pairs (46 mRNA and 13 miRNA) were coordinately expressed. The inverse pairs are the canonical understanding of miRNA:mRNA interactions, meaning that as the expression of one changes, it is expected that the expression of the other will change in the opposite direction. The coordinately expressed pairs can represent either false-positive predictions or positive target regulation. The degree of anticorrelation for the inverse pairs was calculated, and the results are listed in
Table 3. Similarly, the degree of correlation for the coordinate pairs was calculated, and the data are provided in Additional file 6.

\section{Gene ontology and pathway analysis of gene targets} reveals enriched involvement in transcription

To determine whether a particular molecular or biological function or pathway was overrepresented among the 74 predicted target genes, we conducted gene ontology and pathway analysis. According to these results, 23 (31\%) of 74 of the genes regulate transcription. Of the 23, 15 have transcription factor activity, four are transcriptional repressors and nine are sequence-specific DNA-binding factors (see Additional file 7). For example, EGR1 and homeobox A9 (HOXA9) are predicted targets (miR-183:EGR1 and let-7c/miR-182:HOXA9) and are both transcription factors that regulate many genes, including eukaryotic translation initiation factor $4 \mathrm{E}$ (EIF4E), collagen type II, $\alpha 1$ (COL2A1), NAB1 and SNAIL (by EGR1), as well as EIF4E and MEIS2 (by HOXA9). Interestingly, these genes were also differentially expressed in the HN-DCIS comparison, and 


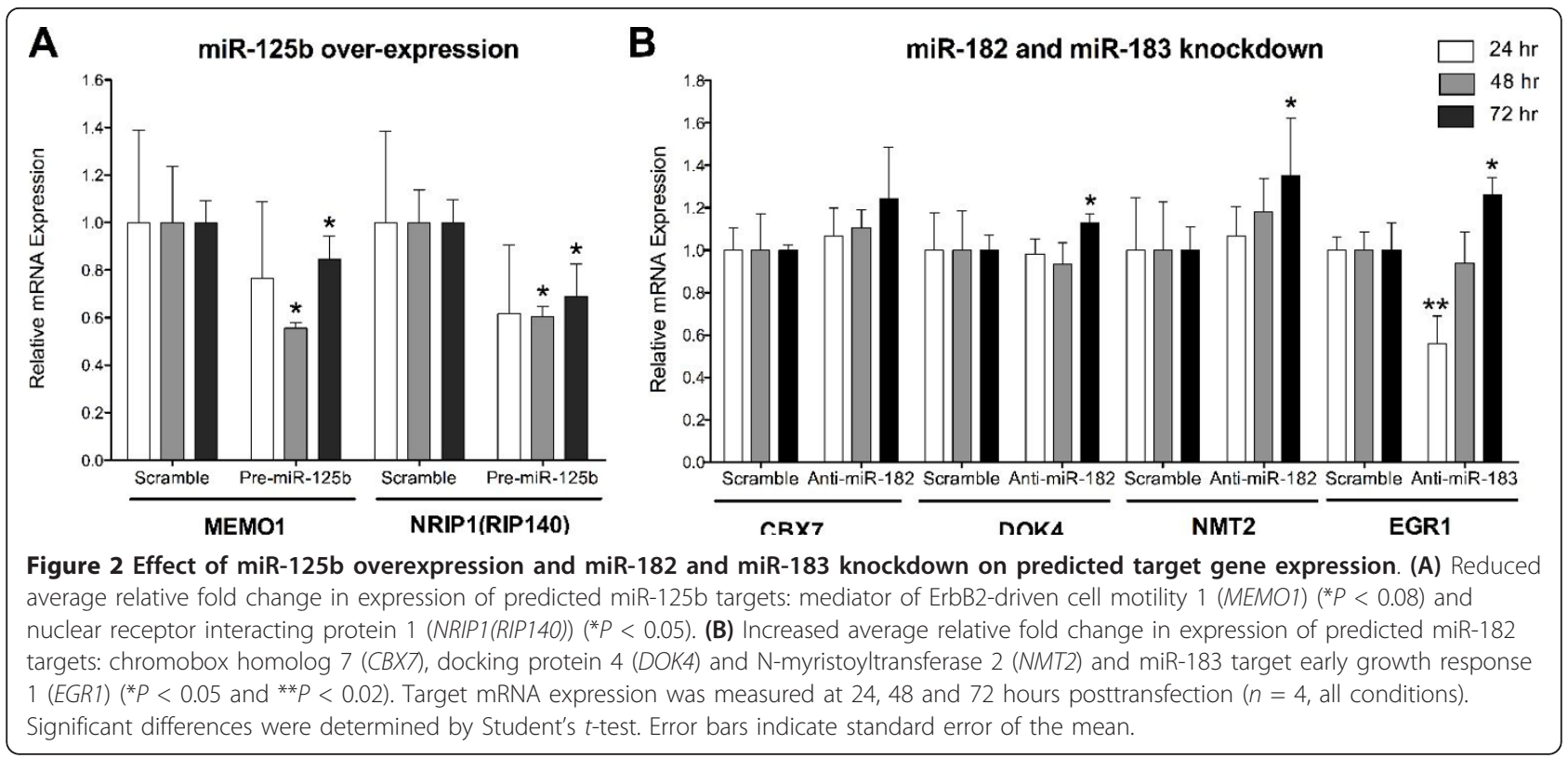

several of these genes are also predicted targets (miR-7: $C O L 2 A 1$, let-7c:NAB1 and let-7c:MEIS2). Because of the use of such a small gene list, no pathways reached a level of significance (see Additional file 8); however, we noted that several genes are associated with cancer-

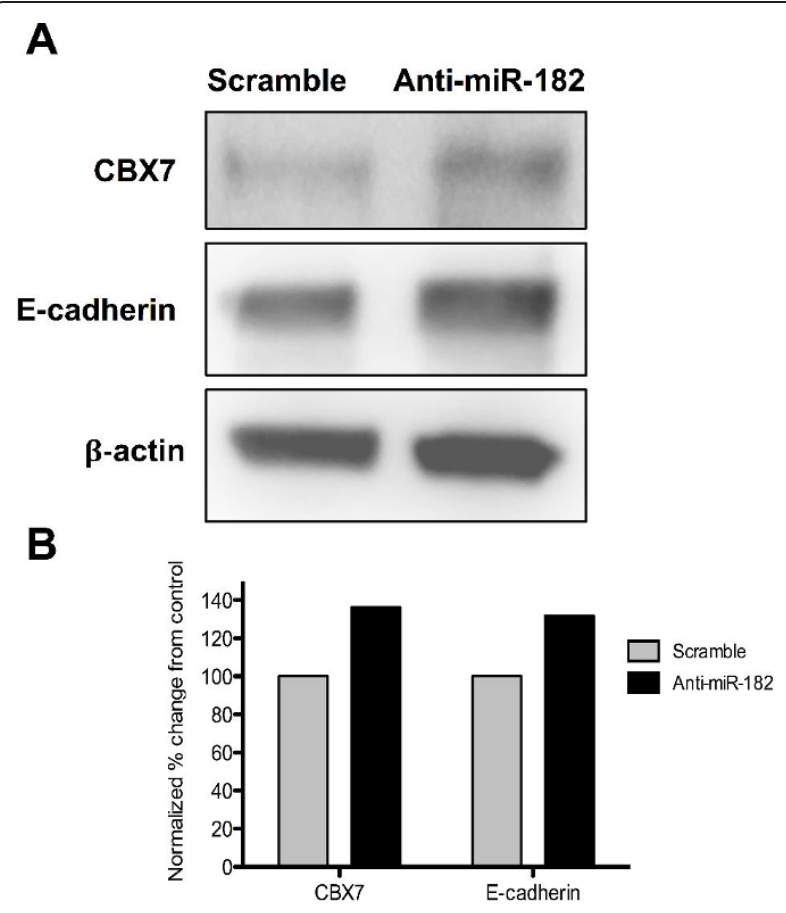

Figure 3 Effect of miR-182 on chromobox homolog 7 (CBX7) and E-cadherin expression. (A) Protein levels of CBX7 and Ecadherin after transfection with anti-miR-182 or scramble. $\beta$-actin served as a loading control. (B) The percentage changes in levels of CBX7 and E-cadherin were quantitated and normalized for $\beta$-actin. related pathways, such as cell cycle regulation (cyclin D1 (CCND1) and YWHAZ), mitogen-activated protein kinase (MAPK) signaling (fibroblast growth factor 2 (FGF2) and DOK4), nucleotide excision repair (RAD23 homolog $\mathrm{B}(R A D 23 B))$ and $p 53$ interactions (CCND1, $C B X 7$, enhancer of zeste homolog 2 (Drosophila) $(E Z H 2), W W$ domain containing E3 ubiquitin protein ligase 1 (WWP1) and PTB4A1).

\section{miR-125b, miR-182 and miR-183 target validation}

Two of the 59 inverse miRNA:mRNA target pairs we identified have been validated: miR-21:NFIB (an oncogenic interaction) in leukemia cells [42] and miR-195: CCND1 (a tumor-suppressive interaction) in hepatocellular carcinoma [43]. Our data suggest a new role for these proven interactions in DCIS.

We wished to validate additional miRNA:mRNA inverse target pairs. On the basis of a high degree of differential expression in DCIS, multiple predicted targets and potential relevance to cancer, we selected six of 59 inverse target pairs consisting of three miRNA (miR125b, miR-182 and miR-183) for experimental manipulation in a breast cancer cell line.

miR-125b expression is greatly reduced in DCIS compared to HN (0.05-fold) and PRM (0.08-fold). Target prediction analysis identified three inverse putative miR125b targets (Table 3). We selected MEMO1 and NRIP1 for validation. $M E M O 1$ is a nonheme iron-dependent dioxygenase that binds to the C-terminus of ErbB2/ Her2 (also a known target of miR-125b) and is required for ErbB2-driven cell motility [29,44]. NRIP1/RIP140 is a nuclear protein that modulates the transcriptional activity of the ER [45]. 
To determine whether MEMO1 and NRIP1 are authentic miR-125b targets, we transiently expressed the precursor of miR-125b in MCF7 cells. This reduced the endogenous expression of MEMO1 as early as 24 hours (0.75-fold), and expression was significantly further decreased at 48 hours ( 0.62 -fold) and remained below baseline at 72 hours (0.84-fold). Similarly, the expression of NRIP1 was reduced at 24 hours $(0.63$-fold), and expression was significantly further decreased at 48 hours (0.53-fold) and remained below baseline at 72 hours (0.68-fold) (Figure 2A). These results suggest that both MEMO1 and NRIP1 are negatively regulated by miR-125b.

miR-182 and miR-183 expression is greatly increased in DCIS compared to HN (72.35- and 51.88-fold, respectively) and to PRM (106.24- and 19.06-fold, respectively), and they are slightly increased in HN compared to PRM (2.0- and 2.52-fold, respectively). Target prediction analysis identified 13 inverse targets of miR182 and four inverse targets of miR-183 (Table 3). We selected $C B X 7, D O K 4$ and NMT2 for miR-182 validation and EGR1 for miR-183 validation. $C B X 7$ is a chromobox family protein and a member of the polycomb-repressive complex 1 that positively regulates E-cadherin expression through interaction with $H D A C 2$ [46]. DOK4 acts as an anchor for $\mathrm{c}$-Src kinase, inhibits tyrosine kinase signaling and can activate MAPK $[47,48]$. NMT2 is a Nmyristoyltransferase, and myristoylated proteins have diverse biological functions in signal transduction and oncogenesis [49]. EGR1 is a $\mathrm{Cys}_{2} \mathrm{His}_{2}$-type zinc finger protein that functions as a transcriptional regulator of target genes required for differentiation and mitogenesis [50].

To determine whether these genes are authentic targets of miR-182 and miR-183, we introduced an antisense RNA specifically designed to knock down the expression of mature miR-182 and miR-183 into MCF7 cells. We observed that from 24 through 72 hours, there was an upward trend in expression for each of the target genes, which was significant for three of the four targets at 72 hours. By 72 hours, the increases in endogenous expression were 1.23-fold for $C B X 7,1.13$-fold for $D O K 4$ and 1.34-fold for NMT2. EGR1 was unexpectedly decreased at 24 hours (0.46-fold), but its expression had returned to baseline at 48 hours and was increased at 72 hours (1.2-fold) (Figure 2B).

\section{Knockdown of miR-182 induces the expression of E- cadherin through upregulation of $C B X 7$}

It has been suggested that the loss of $C B X 7$ expression may influence the invasiveness of epithelial cancers by promoting an epithelial-to-mesenchymal transition [46]. This effect is believed to be due to $C B X 7$ 's ability to promote the expression of E-cadherin, a cell adhesion molecule that plays a role in maintaining normal epithelial cell morphology by associating with and inhibiting the repressive action of $H D A C 2$ within the E-cadherin promoter region. Loss of E-cadherin expression during neoplastic progression is associated with several cancers, including breast cancer. In this study, the expression of $C B X 7$ was reduced 0.44 -fold in the DCIS-HN comparison; however, we did not observe a significant decrease of E-cadherin in our preinvasive clinical samples. It may be that the loss of Ecadherin expression is more characteristic of the invasive transition or of lobular histology. However, we asked whether upregulation of $C B X 7$ due to the reduction of its targeting miRNA (miR-182) would also lead to upregulation of E-cadherin expression in vitro. We found that by 48 hours postknockdown of miR-182, the protein levels of both $C B X 7$ and E-cadherin were upregulated by approximately $35 \%$ to $40 \%$ relative to control (Figures 3A and 3B).

\section{Discussion}

In this study, we identified a set of miRNA that are expressed in normal breast epithelium and found that major miRNA expression changes occur at the transition from normal to DCIS epithelium, thereby defining a set of putative oncogenic and tumor suppressor miRNA that are dysregulated at the preinvasive stage of breast cancer. A greater number of miRNA were expressed in PRM compared to HN and DCIS, which is contrary to what we have observed in our gene expression studies, and we recognize that the high $C_{t}$ cutoff values employed could have influenced these results $[15,16]$. However, this observation fits with the current understanding of miRNA regulation of mRNA expression, given that a greater number of expressed miRNA would correspond to fewer expressed mRNA.

Twenty of these miRNA have previously been implicated in IBC, and $62 \%$ of the miRNA dysregulated in the HN-DCIS comparison are directionally concordant with miRNA dysregulated in IBC. This work identifies a role for these previously implicated miRNA at an early stage of breast cancer development. For example, we found that miR-145 expression was underexpressed in the DCIS-HN comparison. Using an in situ hybridization approach, Sempere et al. [14] found that miR-145 was restricted to the myoepithelial/basal cell compartment of normal mammary ducts and lobules and was reduced or absent in matching tumor specimens. This finding lends support to our discovery of decreased miR-145 in DCIS, because we know that our epithelial samples include myoepithelial cells.

Although we observed a high concordance rate with previous reports in IBC, in contrast to the seminal study by Iorio et al. [13], which examined miRNA expression 
in bulk tumor tissue versus normal tissue, miR-155 was identified as highly overexpressed in breast tumor tissues. However, miR-155 was not differentially expressed in any of our comparisons. This suggests that either miR-155 is an invasive, specific miRNA or its expression is not epithelium-specific, and also that it was detected because of the heterogeneous cell population presenting bulk tumor tissue. miR-155 has since been described in immune cell function, which supports the latter scenario [51]. Comparison of our data set to others may shed light on other miRNA whose expression is specific to either cancer stage or a particular cell type.

The identification of miRNA targets is crucial to the understanding of their biological role. We hypothesized that there is a coordinate mechanism of dysregulation between the abnormal expression of miRNA and target mRNA in very early breast tumorigenesis. By combining miRNA and gene expression data and integrating miRNA target prediction, we obtained a set of candidate miRNA:mRNA target pairs. Approximately onehalf of these target pairs were coordinately expressed and are either false-positive predictions or may in fact positively regulate the target mRNA, albeit a less wellunderstood phenomenon. However, several instances of miRNA-positive regulation of a target gene have been described [52-54]. In addition, it has been noted that two classes of miRNA network motifs, corresponding to positive and negative regulation of a miRNA and its target, may coexist, and in neuronal cells miRNA tend to be coexpressed in the same direction as their target genes [55]. This may in part explain our observations, although further studies are needed.

Our approach has identified many potentially important early-acting, cancer-promoting mRNA targets, and miRNA dysregulation is a potential mechanism causing these early mRNA changes. Many of the identified target genes have known cancer or anticancer activity. For example, TXNIP (thioredoxin-interacting protein), EGR1, CBX7, HOXA9 and FOXN3 (checkpoint repressor 1) have tumor suppressor functions and are targeted by the potentially oncogenic miRNA miR-93, miR-183, miR-181b, miR-182 and miR-7. Similarly, WWP1, SDC1 (syndecan 1), EZH2, CCND1, ADAM9 and MEMO1 have oncogenic activities and are targeted by the potentially tumor suppressor miRNA miR-195, miR-10b, let7c, miR-17 and miR-125b.

Many of these target pairs are likely to be relevant to cancer in general and breast cancer in particular; however, we could validate only a subset of these. We found that with modulation of miR-125b, miR-182 and miR183 expression, we obtained results that suggest these miRNA do regulate the expression of their predicted target genes. The expression of miR-125b is reduced in many cancers, including breast cancer $[13,56]$ and serous ovarian carcinoma [57]. In addition, it has been established that miR-125b targets ErbB2/Her2, and by also targeting $M E M O 1$, which interacts with ErbB2/ Her2, miR-125b is regulating two functionally related genes. $\mathrm{miR}-182$ and $\mathrm{miR}-183$ are clustered at $7 \mathrm{q} 31.2$, a region that is frequently amplified in melanoma [58], and both miRNA are commonly codysregulated in many cancers, including prostate, colon and breast cancer $[33,59,60]$. In this study, we found that by suppressing the expression of miR-182 and miR-183 in vitro, the expression of their four predicted targets, $C B X 7, D O K 4$, NMT2 and EGR1, were upregulated. Two of these, $C B X 7$ and EGR1, have well-described tumor suppressor functions, and recently $D O K 4$ family members ( $D O K 1$, $D O K 2$, and $D O K 3$ ) were identified as lung tumor suppressors [61]. In addition, the secondary effect of miR182 repression resulting in upregulation of E-cadherin through CBX7, which we have shown, may have important implications in reversing epithelial neoplasias to a more normal state. Furthermore, in future studies, combined modulation of miR-125b, miR-182 and/or miR183 , as well as other miRNA altered in DCIS, may be effective in reversing the forward progression to IBC.

Admittedly, our study has several limitations, most notably the small sample size and the inclusion of only ER- and PR-positive DCIS. With the use of microdissected, paired breast tissue samples and robust statistical analysis, we sought to minimize potential biases elicited by small the sample size. In fact, the many similarities between our miRNA expression profile of DCIS and others' miRNA expression profiling of IBC suggest that our results are reliable. However, an expansion of this study to include other histological categories could identify subtype-specific dysregulated miRNA.

\section{Conclusions}

The present study provides the first report of a miRNA expression profile in normal breast epithelium and the first integrated analysis of miRNA and mRNA expression in paired samples of histologically normal and preinvasive breast cancer. We have further demonstrated, by modulating the expression of several miRNA, that the expression of their predicted target genes is affected. Taken together, these findings support our hypothesis that changes in miRNA expression in early breast cancer may control many of the parallel changes in gene expression at this stage. This work also implicates the loss of the tumor suppressor miR-125b and the gain of the oncogenic miRNA miR-182 and miR-183 as major contributors to early breast cancer development. Additionally, this study has revealed novel candidate markers of preinvasive breast cancer, which could contribute to the identification of new diagnostic and therapeutic targets. The miRNA and miRNA:mRNA target pairs 
identified in this study are natural candidates for future investigations.

\section{Additional material}

\section{Additional file 1: LCM series of representative breast epithelial} lesions. Lesions were obtained from healthy normal (RM), histologically normal $(\mathrm{HN})$ and paired adjacent ductal carcinoma in situ (DCIS). Lesions were microdissected from 10- $\mu$ m-thick consecutive tissue sections. Leftright: standard hematoxylin and eosin (H\&E)-stained "guide slide," diluted H\&E-stained precapture and postcapture stromal compartments and captured epithelial compartment. Original magnification, $\times 40$.

\section{Additional file 2: $x$-y scatter correlation plot of triplicate PRM} samples. The cycle threshold $\left(C_{T}\right)$ values for each of the 385 assays from the three replicate PRM samples are plotted against one another. $R^{2}=$ $0.88,0.91$ and 0.90 (mean $=0.90$ ), respectively, and Pearson's correlation coefficients were $0.94,0.96$ and 0.95 (mean $=0.95$ ), respectively.

Additional file 3: List of microRNA considered present or absent in each histological group.

Additional file 4: Expression profiling heatmap of 35 microRNA (miRNA) differentially expressed between PRM, HN and DCIS. Hierarchical clustering heatmap representation of 35 miRNA overexpressed (red) and underexpressed (green) between PRM, HN and DCIS $(P<0.005$, fold change $>3$ ), sorted by physical (chromosomal) position from top to bottom. Black indicates no change in expression. Brackets indicate the 16 clustered miRNA. Rows, miRNA; columns, profiled patient samples; shaded boxes, lesion type or replicate sample.

Additional file 5: All genes significantly differentially expressed in paired $\mathrm{HN}$ and DCIS.

Additional file 6: Expression correlation of microRNA and coordinately expressed predicted targets.

Additional file 7: Enriched gene ontology terms for predicted target genes.

Additional file 8: Cancer-specific functional annotation and pathway analysis of predicted target genes.

\begin{abstract}
Abbreviations
CBX7: chromobox homolog 7; DCIS: ductal carcinoma in situ; DOK4: docking protein 4; EGR1: early growth response 1; HN: histologically normal; MEMO1: mediator of ErbB2-driven cell motility; miRNA: microRNA; mRNA: messenger RNA; NMT2: N-myristoyltransferase 2; NRIP1/RIP140: nuclear receptorinteracting protein 1; RM: reduction mammoplasty; RT-qPCR: real-time quantitative polymerase chain reaction; PRM: pooled reduction mammoplasty.
\end{abstract}

\section{Acknowledgements}

The authors acknowledge PHS award CA115434, the Avon Foundation and the LaPann Foundation for their financial support. BNH is supported by a Predoctoral Traineeship Award from the Department of Defense, USAMRMC W81ZWH-08-1-0254. We thank Kelly Graham, Chialin King and Lyndsey Emery for the use of microarray sample data and Beth Hovey for technical advice regarding immunoblot analysis.

\section{Author details}

'Department of Medicine, Boston Medical Center and Boston University School of Medicine, 72 East Concord Street, Boston, MA 02118, USA. ${ }^{2}$ Department of Biostatistics, Boston University School of Public Health, 715 Albany Street, Boston, MA 02118, USA. ${ }^{3}$ Department of Pathology, Boston Medical Center and Boston University School of Medicine, 72 East Concord Street, Boston, MA 02118, USA.

\section{Authors' contributions}

BNH conceived of and designed the study; executed miRNA expression profiling, subset of gene expression profiling, target prediction and target validation; and drafted the manuscript. PS participated in the design of the study and performed gene and miRNA expression statistical analysis. AdIM reviewed and identified lesions on all histological slides. $J L$ provided expert technical advice and helped to design the validation experiments. CLR conceived of the study, participated in its design and coordination and helped to draft the manuscript. All authors read and approved the final manuscript.

\section{Competing interests}

The authors declare that they have no competing interests.

Received: 21 September 2010 Revised: 24 January 2011

Accepted: 4 March 2011 Published: 4 March 2011

\section{References}

1. Horner MJ, Ries LAG, Krapcho M, Neyman N, Aminou R, Howlader N, Altekruse SF, Feuer EJ, Huang L, Mariotto A, Miller BA, Lewis DR, Eisner MP, Stinchcomb DG, Edwards BK: SEER Cancer Statistics Review, 1975-2006 Bethesda, MD: National Cancer Institute; 2008.

2. Guo H, Ingolia NT, Weissman JS, Bartel DP: Mammalian microRNAs predominantly act to decrease target mRNA levels. Nature 2010, 466:835-840.

3. Krützfeldt J, Stoffel M: MicroRNAs: a new class of regulatory genes affecting metabolism. Cell Metab 2006, 4:9-12.

4. Nimmo RA, Slack FJ: An elegant miRror: microRNAs in stem cells, developmental timing and cancer. Chromosoma 2009, 118:405-418.

5. Cheng AM, Byrom MW, Shelton J, Ford LP: Antisense inhibition of human miRNAs and indications for an involvement of miRNA in cell growth and apoptosis. Nucleic Acids Res 2005, 33:1290-1297.

6. Taft RJ, Pang KC, Mercer TR, Dinger M, Mattick JS: Non-coding RNAs: regulators of disease. J Pathol 2010, 220:126-139.

7. Lu J, Getz G, Miska E, Alvarez-Saavedra E, Lamb J, Peck D, Sweet-Cordero A, Ebert B, Mak R, Ferrando A, Downing J, Jacks T, Horvitz H, Golub T: MicroRNA expression profiles classify human cancers. Nature 2005, 435:834-838.

8. Friedman RC, Farh KK, Burge CB, Bartel DP: Most mammalian mRNAs are conserved targets of microRNAs. Genome Res 2009, 19:92-105.

9. Griffiths-Jones S, Grocock RJ, van Dongen S, Bateman A, Enright AJ: miRBase: microRNA sequences, targets and gene nomenclature. Nucleic Acids Res 2006, 34:D140-D144.

10. Lim LP, Lau NC, Garrett-Engele P, Grimson A, Schelter JM, Castle J, Bartel DP, Linsley PS, Johnson JM: Microarray analysis shows that some microRNAs downregulate large numbers of target mRNAs. Nature 2005, 433:769-773.

11. Mattie MD, Benz CC, Bowers J, Sensinger K, Wong L, Scott GK, Fedele V, Ginzinger D, Getts R, Haqq C: Optimized high-throughput microRNA expression profiling provides novel biomarker assessment of clinical prostate and breast cancer biopsies. Mol Cancer 2006, 5:24.

12. Blenkiron C, Goldstein LD, Thorne NP, Spiteri I, Chin SF, Dunning MJ, Barbosa-Morais NL, Teschendorff AE, Green AR, Ellis IO, Tavaré S, Caldas C, Miska EA: MicroRNA expression profiling of human breast cancer identifies new markers of tumor subtype. Genome Biol 2007, 8:R214.

13. Iorio MV, Ferracin M, Liu CG, Veronese A, Spizzo R, Sabbioni S, Magri E, Pedriali M, Fabbri M, Campiglio M, Ménard S, Palazzo JP, Rosenberg A, Musiani P, Volinia S, Nenci I, Calin GA, Querzoli P, Negrini M, Croce CM: MicroRNA gene expression deregulation in human breast cancer. Cancer Res 2005, 65:7065-7070.

14. Sempere LF, Christensen M, Silahtaroglu A, Bak M, Heath CV, Schwartz G, Wells W, Kauppinen S, Cole CN: Altered MicroRNA expression confined to specific epithelial cell subpopulations in breast cancer. Cancer Res 2007, 67:11612-11620.

15. Emery LA, Tripathi A, King C, Kavanah M, Mendez J, Stone MD, de las Morenas A, Sebastiani P, Rosenberg CL: Early dysregulation of cell adhesion and extracellular matrix pathways in breast cancer progression. Am J Pathol 2009, 175:1292-1302.

16. Tripathi A, King C, de la Morenas A, Perry VK, Burke B, Antoine GA, Hirsch EF, Kavanah M, Mendez J, Stone M, Gerry NP, Lenburg ME, Rosenberg CL: Gene expression abnormalities in histologically normal breast epithelium of breast cancer patients. Int J Cancer 2008, 122:1557-1566.

17. King C, Guo N, Frampton GM, Gerry NP, Lenburg ME, Rosenberg CL: Reliability and reproducibility of gene expression measurements using 
amplified RNA from laser-microdissected primary breast tissue with oligonucleotide arrays. J Mol Diagn 2005, 7:57-64.

18. Li XF, Yan PJ, Shao ZM: Downregulation of miR-193b contributes to enhance urokinase-type plasminogen activator (UPA) expression and tumor progression and invasion in human breast cancer. Oncogene 2009, 28:3937-3948.

19. Churchill GA: Fundamentals of experimental design for CDNA microarrays. Nat Genet 2002, 32(Suppl):490-495.

20. Gentleman RC, Carey VJ, Bates DM, Bolstad B, Dettling M, Dudoit S, Ellis B, Gautier L, Ge Y, Gentry J, Hornik K, Hothorn T, Huber W, lacus S, Irizarry R, Leisch F, Li C, Maechler M, Rossini AJ, Sawitzki G, Smith C, Smyth G, Tierney L, Yang JY, Zhang J: Bioconductor: open software development for computational biology and bioinformatics. Genome Biol 2004, 5:R80

21. Graham K, de las Morenas A, Tripathi A, King C, Kavanah M, Mendez J, Stone M, Slama J, Miller M, Antoine G, Willers H, Sebastiani P, Rosenberg CL: Gene expression in histologically normal epithelium from breast cancer patients and from cancer-free prophylactic mastectomy patients shares a similar profile. Br J Cancer 2010, 102:1284-1293.

22. BADGE (Bayesian Analysis of Differential Gene Expression). [http:// dcommon.bu.edu/xmlui/handle/2144/1289].

23. Creighton CJ, Nagaraja AK, Hanash SM, Matzuk MM, Gunaratne PH: A bioinformatics tool for linking gene expression profiling results with public databases of microRNA target predictions. RNA 2008, 14:2290-2296

24. Krek A, Grün D, Poy M, Wolf R, Rosenberg L, Epstein E, MacMenamin P, da Piedade I, Gunsalus K, Stoffel M, Rajewsky N: Combinatorial microRNA target predictions. Nat Genet 2005, 37:495-500.

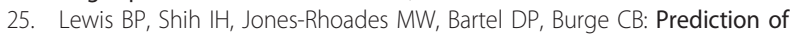
mammalian microRNA targets. Cell 2003, 115:787-798.

26. Betel D, Wilson M, Gabow A, Marks DS, Sander C: The microRNA.org resource: targets and expression. Nucleic Acids Res 2008, 36:D149-D153.

27. Huang da W, Sherman BT, Lempicki RA: Systematic and integrative analysis of large gene lists using DAVID bioinformatics resources. Nat Protoc 2009, 4:44-57.

28. Baskerville S, Bartel DP: Microarray profiling of microRNAs reveals frequent coexpression with neighboring miRNAs and host genes. RNA 2005, 11:241-247.

29. Scott GK, Goga A, Bhaumik D, Berger CE, Sullivan CS, Benz CC: Coordinate suppression of ERBB2 and ERBB3 by enforced expression of micro-RNA miR-125a or miR-125b. J Biol Chem 2007, 282:1479-1486.

30. Saito $Y$, Liang G, Egger G, Friedman JM, Chuang JC, Coetzee GA, Jones PA: Specific activation of microRNA-127 with downregulation of the protooncogene $B C L 6$ by chromatin-modifying drugs in human cancer cells. Cancer Cell 2006, 9:435-443.

31. Yan LX, Huang XF, Shao Q, Huang MY, Deng L, Wu QL, Zeng YX, Shao JY: MicroRNA miR-21 overexpression in human breast cancer is associated with advanced clinical stage, lymph node metastasis and patient poor prognosis. RNA 2008.

32. Yu Z, Wang C, Wang M, Li Z, Casimiro MC, Liu M, Wu K, Whittle J, Ju X, Hyslop T, McCue P, Pestell RG: A cyclin D1/microRNA 17/20 regulatory feedback loop in control of breast cancer cell proliferation. J Cell Biol 2008, 182:509-517.

33. Guttilla IK, White BA: Coordinate regulation of FOXO1 by miR-27a, miR96, and miR-182 in breast cancer cells. J Biol Chem 2009, 284:23204-23216.

34. Zhang L, Huang J, Yang N, Greshock J, Megraw M, Giannakakis A, Liang S, Naylor T, Barchetti A, Ward M, Yao G, Medina A, O'Brien-Jenkins A, Katsaros D, Hatzigeorgiou A, Gimotty P, Weber B, Coukos G: microRNAs exhibit high frequency genomic alterations in human cancer. Proc Natl Acad Sci USA 2006, 103:9136-9141.

35. Zhang H, Su SB, Zhou QM, Lu YY: [Differential expression profiles of microRNAs between breast cancer cells and mammary epithelial cells] [in Chinese]. Ai Zheng 2009, 28:493-499.

36. Frankel LB, Christoffersen NR, Jacobsen $A$, Lindow $M$, Krogh $A$, Lund $A H$ : Programmed cell death 4 (PDCD4) is an important functional target of the microRNA miR-21 in breast cancer cells. J Biol Chem 2008, 283:1026-1033.

37. Gregory PA, Bert AG, Paterson EL, Barry SC, Tsykin A, Farshid G, Vadas MA, Khew-Goodall Y, Goodall GJ: The miR-200 family and miR-205 regulate epithelial to mesenchymal transition by targeting ZEB1 and SIP1. Nat Cell Biol 2008, 10:593-601.

38. Foekens JA, Sieuwerts AM, Smid M, Look MP, de Weerd V, Boersma AW, Klijn JG, Wiemer EA, Martens JW: Four miRNAs associated with aggressiveness of lymph node-negative, estrogen receptor-positive human breast cancer. Proc Natl Acad Sci USA 2008, 105:13021-13026.

39. Ma L, Teruya-Feldstein J, Weinberg RA: Tumour invasion and metastasis initiated by microRNA-10b in breast cancer. Nature 2007, 449:682-688.

40. Volinia S, Calin GA, Liu CG, Ambs S, Cimmino A, Petrocca F, Visone R, lorio M, Roldo C, Ferracin M, Prueitt RL, Yanaihara N, Lanza G, Scarpa A, Vecchione A, Negrini M, Harris CC, Croce CM: A microRNA expression signature of human solid tumors defines cancer gene targets. Proc Natl Acad Sci USA 2006, 103:2257-2261.

41. Si ML, Zhu S, Wu H, Lu Z, Wu F, Mo YY: miR-21-mediated tumor growth: suppression of tumor growth by anti-miR-21. Oncogene 2007, 26:2799-2803.

42. Fujita S, Ito T, Mizutani T, Minoguchi S, Yamamichi N, Sakurai K, Iba H: miR21 gene expression triggered by AP-1 is sustained through a doublenegative feedback mechanism. J Mol Biol 2008, 378:492-504.

43. Xu T, Zhu Y, Xiong Y, Ge YY, Yun JP, Zhuang SM: MicroRNA-195 suppresses tumorigenicity and regulates G1/S transition of human hepatocellular carcinoma cells. Hepatology 2009, 50:113-121.

44. Qiu C, Lienhard S, Hynes NE, Badache A, Leahy DJ: Memo is homologous to nonheme iron dioxygenases and binds an ErbB2-derived phosphopeptide in its vestigial active site. J Biol Chem 2008, 283:2734-2740

45. Cavaillès V, Dauvois S, L'Horset F, Lopez G, Hoare S, Kushner PJ, Parker MG: Nuclear factor RIP140 modulates transcriptional activation by the estrogen receptor. EMBO J 1995, 14:3741-3751.

46. Federico A, Pallante P, Bianco M, Ferraro A, Esposito F, Monti M, Cozzolino M, Keller S, Fedele M, Leone V, Troncone G, Chiariotti L, Pucci P, Fusco A: Chromobox protein homologue 7 protein, with decreased expression in human carcinomas, positively regulates $\mathrm{E}$-cadherin expression by interacting with the histone deacetylase 2 protein. Cancer Res 2009, 69:7079-7087.

47. Itoh S, Lemay S, Osawa M, Che W, Duan Y, Tompkins A, Brookes PS, Sheu SS, Abe J: Mitochondrial Dok-4 recruits Src kinase and regulates NF-KB activation in endothelial cells. J Biol Chem 2005, 280:26383-26396.

48. Bedirian A, Baldwin C, Abe J, Takano T, Lemay S: Pleckstrin homology and phosphotyrosine-binding domain-dependent membrane association and tyrosine phosphorylation of Dok-4, an inhibitory adapter molecule expressed in epithelial cells. J Biol Chem 2004, 279:19335-19349.

49. Selvakumar P, Pasha MK, Ashakumary L, Dimmock JR, Sharma RK: MyristoylCoA:protein N-myristoyltransferase: a novel molecular approach for cancer therapy. Int J Mol Med 2002, 10:493-500.

50. Baron V, Adamson ED, Calogero A, Ragona G, Mercola D: The transcription factor Egr1 is a direct regulator of multiple tumor suppressors including TGF $\beta 1$, PTEN, p53, and fibronectin. Cancer Gene Ther 2006, 13:115-124.

51. Rodriguez $A$, Vigorito $E$, Clare $S$, Warren $M$, Couttet $P$, Soond $D$, van Dongen S, Grocock R, Das P, Miska E, Vetrie D, Okkenhaug K, Enright A, Dougan $G$, Turner M, Bradley A: Requirement of bic/microRNA-155 for normal immune function. Science 2007, 316:608-611.

52. Vasudevan $S$, Tong $Y$, Steitz JA: Switching from repression to activation: microRNAs can up-regulate translation. Science 2007, 318:1931-1934.

53. Tsai NP, Lin YL, Wei LN: MicroRNA mir-346 targets the $5^{\prime}$-untranslated region of receptor-interacting protein 140 (RIP140) mRNA and upregulates its protein expression. Biochem J 2009, 424:411-418.

54. Place RF, Li LC, Pookot D, Noonan EJ, Dahiya R: MicroRNA-373 induces expression of genes with complementary promoter sequences. Proc Natl Acad Sci USA 2008, 105:1608-1613.

55. Tsang J, Zhu J, van Oudenaarden A: MicroRNA-mediated feedback and feedforward loops are recurrent network motifs in mammals. Mol Cell 2007, 26:753-767.

56. Hui AB, Shi W, Boutros PC, Miller N, Pintilie M, Fyles T, McCready D, Wong D, Gerster K, Waldron L, Jurisica I, Penn LZ, Liu FF: Robust global micro-RNA profiling with formalin-fixed paraffin-embedded breast cancer tissues. Lab Invest 2009, 89:597-606.

57. Nam EJ, Yoon H, Kim SW, Kim H, Kim YT, Kim JH, Kim JW, Kim S: MicroRNA expression profiles in serous ovarian carcinoma. Clin Cancer Res 2008, 14:2690-2695. 
58. Segura MF, Hanniford D, Menendez S, Reavie L, Zou X, Alvarez-Diaz S, Zakrzewski J, Blochin E, Rose A, Bogunovic D, Polsky D, Wei J, Lee P, Belitskaya-Levy I, Bhardwaj N, Osman I, Hernando E: Aberrant miR-182 expression promotes melanoma metastasis by repressing $\mathrm{FOXO} 3$ and microphthalmia-associated transcription factor. Proc Natl Acad Sci USA 2009, 106:1814-1819.

59. Sarver AL, French AJ, Borralho PM, Thayanithy V, Oberg AL, Silverstein KA, Morlan BW, Riska SM, Boardman LA, Cunningham JM, Subramanian S, Wang L, Smyrk TC, Rodrigues CM, Thibodeau SN, Steer CJ: Human colon cancer profiles show differential microRNA expression depending on mismatch repair status and are characteristic of undifferentiated proliferative states. BMC Cancer 2009, 9:401.

60. Schaefer A, Jung M, Mollenkopf HJ, Wagner I, Stephan C, Jentzmik F, Miller K, Lein M, Kristiansen G, Jung K: Diagnostic and prognostic implications of microRNA profiling in prostate carcinoma. Int I Cancer 2010, 126:1166-1176.

61. Berger AH, Niki M, Morotti A, Taylor BS, Socci ND, Viale A, Brennan C, Szoke J, Motoi N, Rothman PB, Teruya-Feldstein J, Gerald WL, Ladanyi M, Pandolfi PP: Identification of DOK genes as lung tumor suppressors. Nat Genet 2010, 42:216-223.

62. Zhao Y, Deng C, Wang J, Xiao J, Gatalica Z, Recker RR, Xiao GG: Let-7 family miRNAs regulate estrogen receptor alpha signaling in estrogen receptor positive breast cancer. Breast Cancer Res Treat 2010.

doi:10.1186/bcr2839

Cite this article as: Hannafon et al: Expression of microRNA and their gene targets are dysregulated in preinvasive breast cancer. Breast Cancer Research 2011 13:R24.

\section{Submit your next manuscript to BioMed Central} and take full advantage of:

- Convenient online submission

- Thorough peer review

- No space constraints or color figure charges

- Immediate publication on acceptance

- Inclusion in PubMed, CAS, Scopus and Google Scholar

- Research which is freely available for redistribution

Submit your manuscript at www.biomedcentral.com/submit
C Biomed Central 